biosynthesis in vitro. I. Enhancement of IgE and IgG synthesis in the presence of pokeweed mitogen by T-cell irradiation. J Allergy Clin Immunol 71:212223

16. Tomasi TB Jr 1982 Secretory immunoglobulins. N Engl J Med 287:500-506

17. Newcomb R, Ishizaka K 1970 Physiochemical and antigenic studies on human IgE in respiratory fluids. J Immunol 105:85-89

18. Nakajima S, Gillespie DN, Gleich GJ 1975 Differences between IgA and IgE as secretory proteins. Clin Exp Immunol 21:306-317

19. Chanock RM, Kim HW, Brandt CD, Parrott RH 1982 Respiratory syncytial virus. In: Evans AS (ed) Viral Infections of Humans: Epidemiology and Control. Plenum Medical Book Company, New York, pp 471-488

20. Welliver RC, Kaul TN, Putnam TI, Sun M, Riddlesberger K, Ogra PL 1980 The antibody response to primary and secondary infection with respiratory syncytial virus: kinetics of class-specific responses. J Pediatr 96:808-813
21. Kaul TN, Welliver RC, Wong DT, Udwadia RA, Riddlesberger K, Ogra PL 1981 Secretory antibody response to respiratory syncytial virus infection. Am J Dis Child 135:1013-1016

22. McDermott MR, Bienenstock T 1979 Evidence for a common mucosal immunologic system. I. Migration of B immunoblasts into intestinal, respiratory, and genital tissues. J Immunol 122:1892-1898

23. Katz DH, Bargatze RF, Bogowitz CA, Matz LR 1980 Regulation of IgE antibody production by serum molecules. VII. The IgE-selective damping activity of suppressive factor of allergy (SFA) is exerted across both strain and species restriction barriers. J Immunol 124:819-824

24. Zuraw BL, Noaka M, O'Hair C, Katz DH 1981 Human IgE antibody synthesis in vitro: stimulation of $\mathrm{IgE}$ response by pokeweed mitogen and selective inhibition of such responses by human suppressive factor of allergy (SFA). $J$ Immunol 127:1169-1174

\title{
Hypouricemia in Neonates with Syndrome of Inappropriate Secretion of Antidiuretic Hormone
}

\author{
FARAHNAK K. ASSADI AND EUNICE G. JOHN
}

Department of Pediatrics, University of Illinois Health Sciences Center, Chicago, Illinois 60612

\begin{abstract}
A prospective study of serum levels of uric acid in 23 hyponatremic neonates was performed. Infants on diuretic medications or with renal failure were excluded. The infants were separated into two groups: group I consisted of 11 neonates with clinical evidence of syndrome of inappropriate secretion of antidiuretic hormone (SIADH), (mean \pm SD serum sodium $127 \pm 1.36 \mathrm{mEq} /$ liter). Group II included 12 infants with hyponatremia (mean serum sodium $128 \pm 1.10 \mathrm{mEq} /$ liter) associated with decreased effective vascular volume manifest by a fractional sodium excretion $<1 \%$. The groups were similar for gestational and postnatal ages, birth weight, clinical conditions, and concurrent use of drugs. The serum urate concentation in neonates with SIADH was $2.46 \pm 0.54 \mathrm{mg} / \mathrm{dl}$; serum urate concentration in group II infants was $8.49 \pm 2.45 \mathrm{mg} / \mathrm{dL}$ $(p<0.001)$. Water restriction in the group I infants with SIADH resulted in a rise in mean serum urate concentration $(p<0.001)$. Fractional excretion of urate was elevated during hyponatremia in the group I infants (to $78 \pm 0.13 \%$ ) and fell to $51 \pm 0.08 \%$ after correction $(p<0.001)$. In group I infants, a direct correlation was found between fractional excretion of urate and sodium $(r=0.7667, p<$ 0.001 ). These results indicate that hypouricemia is common in infants with suspected SIADH and seems to be due to increased urate clearance secondary to volume expansion. (Pediatr Res 19: 424-427, 1985)
\end{abstract}

\section{Abbreviations}

SIADH, syndrome of inappropriate secretion of antidiuretic hormone

$\mathrm{FE}_{\mathrm{Na}}$, fractional sodium excretion

SUr, serum urate concentration

Received September 27, 1984; accepted December 21, 1984

Reprint requests Dr. Farahnak K. Assadi, Department of Pediatrics, University of Illinois Health Sciences Center, 840 South Wood Street, Chicago, IL 60612.
FE $_{\text {Ur, }}$ fractional urate excretion ECFV, extracellular fluid volume AVP, arginine vasopressin

$\mathrm{C}_{\mathrm{Cr}}$, creatinine clearance

The diagnosis of SIADH in neonates and its differentiation from other common causes of hyponatremia is often difficult (1-6). In the syndrome of SIADH, dilution of body fluids occurs because of the inability of the kidney to excrete free water appropriately. Total body sodium content is normal or only moderately decreased; intravascular volume is slightly increased $(7,8)$. In most other hyponatremic syndromes there is either a marked increase (as in edematous states) or a marked decrease in total body sodium (as in true hypovolemia). In these latter conditions, excretion of water by the kidney may be impaired as a result of the decrease in effective intravascular volume (9). This in turn may cause decreased delivery of glomerular filtrate to distal nephron sites of dilution (10) or may initiate a nonosmolar stimulus to pituitary antidiuretic hormone release (9).

The present study was conducted to test the hypothesis that the "effective intravascular volume" is a potent modulator of renal urate clearance by the kidney and that SUr might reflect changes in effective volume (11-13).

\section{PATENTS AND METHODS}

Twenty-three newborn infants with postnatal ages ranging from 2 to 7 days were evaluated because of hyponatremia (serum sodium concentration $<130 \mathrm{mEq} /$ liter) and hypoosmolality of body fluids (serum osmolality $<270 \mathrm{mOsmol} / \mathrm{kg}$ ) of 1 to 3 days duration. Patients with evidence of renal insufficiency (abnormal urinary sediment, serum concentration of creatinine of greater than $1 \mathrm{mg} / \mathrm{dl}$ ) were excluded from study. Also excluded were 
patients who had received diuretic agents. No patient had undergone a radiologic dye study. The patients were separated into two groups. Group I included 11 patients with probable SIADH with a mean gestational age of $34 \mathrm{wk}$ and mean birth weight of 1935 g. Group II contained the remaining 12 patients with hyponatremia with a mean gestational age of 34.5 wk and a mean birth weight of $1870 \mathrm{~g}$.

The presumptive diagnosis of SIADH was based on the following criteria: hypoosmolality of body fluids (as defined above), urinary osmolality of $>300 \mathrm{mOsmol} / \mathrm{kg}$, absence of edema or clinical signs of volume depletion, normal creatinine clearance, and absence of clinical evidence of endocrine deficiency $(7,8)$. Sepsis, pulmonary, and/or central nervous system abnormalities were present in all group I patients, and all required assisted ventilation. Of the 12 group II patients, eight had clinical signs of sodium depletion, usually due to gastrointestinal loss, and four manifested congestive heart failure with sodium overload and edema. All patients in group II had prerenal azotemia, with $\mathrm{FE}_{\mathrm{Na}}$ of $<1 \%$ suggesting decreased effective intravascular volume (14). The associated clinical conditions in group II included respiratory distress syndrome, sepsis, necrotizing enterocolitis, and intracranial bleeding. Most patients in this group required assisted ventilation (nine of 12).

Group I and II patients were similar with regard to concurrent use of medications and none had been given a hypouricemic agent. Fluid intake in each patient prior to the diagnosis of hyponatremia was 120 to $150 \mathrm{ml} / \mathrm{kg} /$ day and was adjusted to maintain a urine production rate of $>3 \mathrm{ml} / \mathrm{kg} / \mathrm{h}$. Sodium intake was $3 \mathrm{mEq} / \mathrm{kg} /$ day.

Accurately timed 4- to 6-h urine samples were collected from each infant using a plastic urine bag. An arterialized capillary blood specimen $(1 \mathrm{ml})$ was obtained during the urine collection and the serum was separated by rapid centrifugation $(3000 \mathrm{rpm}$ $\times 5 \mathrm{~min}$ ) at room temperature. Each urine and serum sample was frozen at $-20^{\circ} \mathrm{C}$ after collections were completed. Creatinine content of serum and urine was measured with a Beckman Creatinine Analyzer. Sodium was measured by flame photometry and uric acid with an iron reduction method. Filtered urate was calculated as the product of SUr and glomerular filtration rate (GFR). GFR was measured by endogenous $\mathrm{C}_{\mathrm{Cr}}$. $\mathrm{FE}_{\mathrm{Ur}}, \mathrm{FE}_{\mathrm{Na}}$, and free water clearance $\left(\mathrm{C}_{\mathrm{H} 2 \mathrm{O}}\right)$ were derived from the following formulas:

$$
\begin{aligned}
& \mathrm{FE}_{\mathrm{Ur}}=\mathrm{C}_{\mathrm{Ur}} / \mathrm{C}_{\mathrm{Cr}} \times 100 \\
& \mathrm{FE}_{\mathrm{Na}}=\mathrm{C}_{\mathrm{Na}} / \mathrm{C}_{\mathrm{Cr}} \times 100 \\
& \mathrm{C}_{\mathrm{H}_{2} \mathrm{O}}=\mathrm{V}-\mathrm{C}_{\text {Osmol }}
\end{aligned}
$$

where $\mathrm{C}_{\mathrm{Ur}}=$ urate clearance, $\mathrm{C}_{\mathrm{Na}}=$ sodium clearance; and $\mathrm{C}_{\mathrm{Osmol}}$ $=$ osmolar clearance. All clearance studies were carried out during the period of hyponatremia.

Mean values in the two groups were compared using Student's two-tailed $t$ test (15). Values are recorded as mean and SD. The study was approved by the University of Illinois Health Sciences Center Institutional Review Committee on Human Research.

\section{RESULTS}

The mean serum sodium concentration in the group I SIADH newborns was $127 \pm 0.36 \mathrm{mEq} / \mathrm{liter}$, a value similar to that in the group II infants (serum sodium $=128 \pm 1.10 \mathrm{mEq} / \mathrm{liter}$ ).

Figure 1 shows the individual SUr in the two groups of patients. The mean SUr in the infants with SIADH was $2.64 \pm 0.54 \mathrm{mg} /$ dl. In group II patients, the mean value was $8.49 \pm 2.45 \mathrm{mg} / \mathrm{dl}$ $(p<0.001)$. The absolute SUr was $<3.1 \mathrm{mg} / \mathrm{dl}$ in all 11 neonates with SIADH, whereas all patients with other causes of hyponatremia had values of $4 \mathrm{mg} / \mathrm{dl}$ or more.

To determine whether the relative hypouricemia in the SIADH infants was more closely related to the underlying disease or to the hyponatremia, SUr was assessed after correction of the hyponatremia by water restriction. For this purpose, daily maintenance fluid intake was restricted $50 \%$ over a period of 24 to 48 h. The mean SUr in these patients rose from $2.46 \pm 0.54$ to 4.95

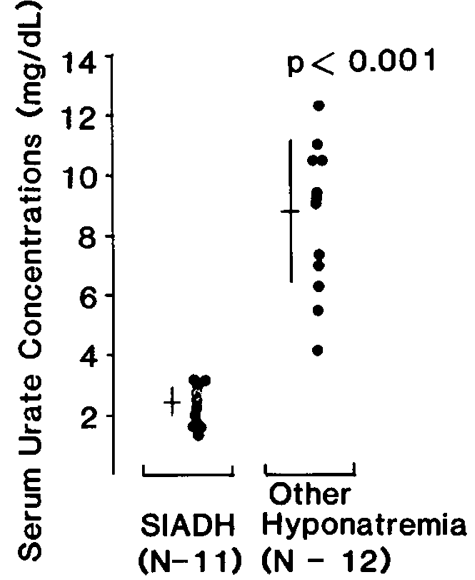

Fig. 1. Serum urate concentrations are compared in newborns with presumptive SIADH and those with decreased effective vascular volume. Mean values \pm SD are given by horizontal and vertical lines, respectively, number of patients are given in parentheses.

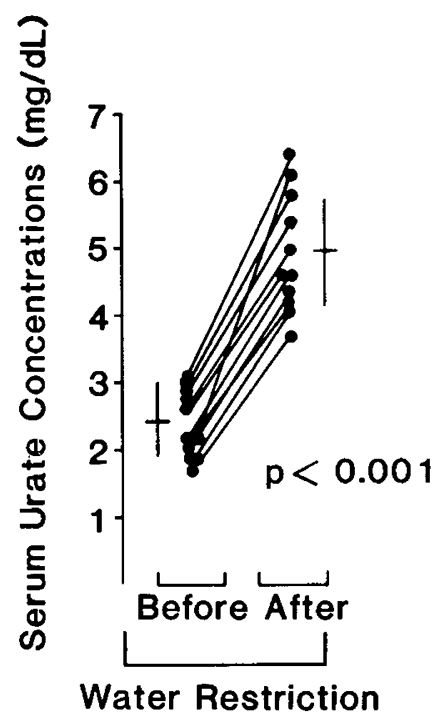

Fig. 2. Serum urate concentrations are compared before and after water restriction in infants with a presumptive diagnosis of SIADH. Mean values $\pm \mathrm{SD}$ are given by horizontal and vertical lines, respectively, number of patients are given in parentheses.

$\pm 0.86 \mathrm{mg} / \mathrm{dl}(p<0.001)$ after correction of hyponatremia. Moreover, as shown in Figure 2, the change in serum urate was consistent and occurred in every patient as serum osmolality was restored to normal.

To examine the pathophysiology of hypouricemia in SIADH, creatinine, urate, and free water clearance studies were performed before and after water restriction in the group I infants. Table 1 summarizes the results. Urate clearance $(2.31 \pm 0.68 \mathrm{ml} / \mathrm{min})$, $\mathrm{FE}_{\mathrm{Na}}(4.25 \pm 0.67 \%)$, and $\mathrm{FE}_{\mathrm{Ur}}(78 \pm 0.3 \%)$ were elevated at the time of hyponatremia but fell significantly with restoration of normal plasma osmolality by water restriction $(1.46 \pm 0.36 \mathrm{ml} /$ min, $2.5 \pm 0.29 \%$, and $51 \pm 0.08 \%$, respectively, each $p<0.001$ ). As shown in Figure 3, the change in $\mathrm{FE}_{\mathrm{Ur}}$ was consistent and occurred in every patient as hypoosmolality was corrected. In all studies, there was a direct and significant correlation between $\mathrm{FE}_{\mathrm{Ur}}$ and $\mathrm{FE}_{\mathrm{Na}}(r=0.7667, p<0.001$, Fig. 4).

\section{DISCUSSION}

The criteria for a presumptive clinical diagnosis of SIADH include hyponatremia and hypoosmolality of body fluids with 
Table 1. Summary of clearance studies in 11 neonates with the SIADH (mean $\pm S D)^{*}$

\begin{tabular}{lccc}
\hline & \multicolumn{3}{c}{ Fluid restriction } \\
\cline { 2 - 4 } & Before & After & $p$ \\
\hline $\mathrm{Wt}(\mathrm{g})$ & $1935 \pm 18$ & $1863 \pm 11$ & $<0.05$ \\
$\mathrm{SNa}(\mathrm{mEq} / \mathrm{liter})$ & $127 \pm 1.36$ & $136 \pm 1.05$ & $<0.05$ \\
$\mathrm{SOsm}(\mathrm{mOsmol} / \mathrm{kg})$ & $262 \pm 2.28$ & $276 \pm 2.77$ & $<0.01$ \\
$\mathrm{SUr}(\mathrm{mg} / \mathrm{dl})$ & $2.46 \pm 0.54$ & $4.95 \pm 0.86$ & $<0.001$ \\
$\mathrm{~V}(\mathrm{ml} / \mathrm{min})$ & $0.07 \pm 0.01$ & $0.04 \pm 0.01$ & $<0.01$ \\
$\mathrm{UOsm}(\mathrm{mOsmol} / \mathrm{kg})$ & $328 \pm 5.31$ & $676 \pm 13.8$ & $<0.01$ \\
$\mathrm{C}_{\mathrm{Cr}}(\mathrm{ml} / \mathrm{min})$ & $2.99 \pm 1.01$ & $2.93 \pm 1.01$ & $\mathrm{NS}$ \\
$\mathrm{F} . \mathrm{Ur}(\mathrm{mg} / \mathrm{min})$ & $7.25 \pm 3.08$ & $14.23 \pm 4.77$ & $<0.001$ \\
$\mathrm{C}_{\mathrm{Ur}}(\mathrm{ml} / \mathrm{min})$ & $2.31 \pm 0.68$ & $1.46 \pm 0.36$ & $<0.001$ \\
$\mathrm{FE}_{\mathrm{Ur}}(\%)$ & $78 \pm 1.30$ & $51 \pm 0.08$ & $<0.001$ \\
$\mathrm{FE}_{\mathrm{Na}}(\%)$ & $4.25 \pm 0.67$ & $2.57 \pm 0.29$ & $<0.001$ \\
$\mathrm{C}_{\mathrm{H}_{2} \mathrm{O}}(\mathrm{ml} / \mathrm{min})$ & -0.01 & -0.05 & $<0.05$ \\
\hline
\end{tabular}

*Abbreviations: SNa, serum sodium; SOsm, serum osmolality; $\mathrm{V}$, urine flow; UOsm, urine osmolality; F.Ur, filtered load of urate; $\mathrm{C}_{\mathrm{Ur}}$, urate clearance; $\mathrm{C}_{\mathrm{H}_{2} \mathrm{O}}$, free water clearance.

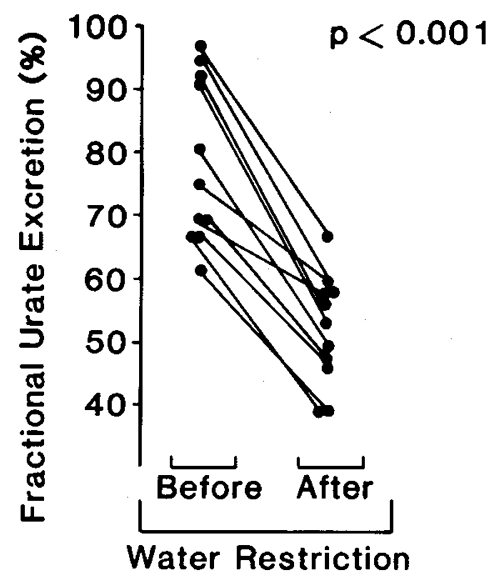

Fig. 3. Fractional urate excretion is compared before and after water restriction in the presumptive SIADH patients. Mean values \pm SD are given by horizontal and vertical lines, respectively, number of patients are given in parentheses.

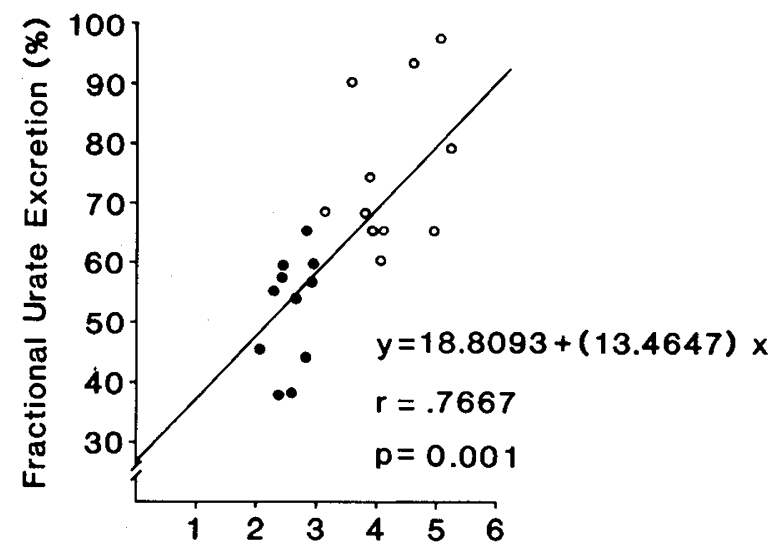

Fractional Sodium Excretion (\%)

Fig. 4. Correlation betwen fractional urate excretion and fractional sodium excretion in neonates with presumptive SIADH, before $(O)$ and after (๑) water restriction.

simultaneous inappropriate osmolality of urine, which contains appreciable amounts of sodium, in a patient who shows no signs of hypovolemia and has normal renal and adrenal functions (7, 8). In the present study, group I infants met these diagnostic criteria. Plasma or urine AVP concentrations were not measured in these patients; thus, the diagnosis was not definitive $(6,16$, 17).

Alterations of ECFV previously have been demonstrated to lead to changes in net tubular reabsorption of urate $(11,13)$. Urate is thought to be nearly completely filtered at the glomerulus. In the renal tubule urate is reabsorbed and secreted by relatively specific tubular transport processes (18); the amount of urate finally excreted in the urine appears to depend on the balance between tubular secretion and postsecretory reabsorption $(11,19,20)$. Renal tubular urate transport is sensitive to many influences including the serum concentration of urate, changes in ECFV $(12,13)$, and age-related maturation of renal function during the early days of life (21). Expansion of ECFV increases urate clearance by inhibiting tubular reabsorption $(12,13)$; contraction of ECFV decreases the urate clearance, probably by enhancing tubular reabsorption. SUr, in turn, reflects the changes in urate clearance $(12,13)$.

In SIADH, there is usually some degree of volume expansion which leads to an increased clearance of urate and hypouricemia (22). This can be corrected by restriction of fluid intake and amelioration of volume expansion (23). The results of the present study are consistent with this hypothesis. The SUr in newborn infants is slightly higher than the values reported for children and adults (24-26). In normal infants, SUr increases from a mean value of $6.0 \mathrm{mg} / \mathrm{dl}$ in cord blood to $7.0 \mathrm{mg} / \mathrm{dl}$ at $24 \mathrm{~h} \mathrm{(26).}$ Prolonged labor and respiratory distress tend to be associated with even higher SUr concentrations in the neonate (26). This relative hyperuricemia is thought to be the result of increase urate production; uric acid excretion does not appear to be limited by the immaturity of the neonatal kidney $(26,28,29)$. In neonates, the mean $\mathrm{FE}_{\mathrm{Ur}}$ is nearly three time the upper normal adult limit (28). Values as high as $70 \%$ are observed at 29 to 31 wk gestation; the mean value at term is $38 \%$ (29). The high $\mathrm{FE}_{\mathrm{Ur}}$ during the neonatal period reflects increased tubular secretion, decreased tubular reabsorption, or both $(28,29)$.

The finding of low SUr in virtually every neonate with SIADH in our study is consistent with observations in adults with this syndrome $(22,23)$. The highest SUr in the present SIADH infants was $3.1 \mathrm{mg} / \mathrm{dl}$. In sharp contrast, all hyponatremic patients in group II had SUr $>4.0 \mathrm{mg} / \mathrm{dl}$. Thus the two groups could be distinguished on the basis of SUr. The hypouricemia in the infants with SIADH could not have been merely a result of dilution since SUr values rose $100 \%$ during water restriction, whereas the serum concentrations of sodium increased only $5 \%$.

Hypouricemia in SIADH may be caused by decreased urate production, increased urinary excretion of urate, or both. Although 24-h urinary excretion of urate was not measured in our patients, $\mathrm{FE}_{\mathrm{Ur}}$ was high in every patient with the syndrome, a finding that probably excludes decreased production as a cause of hypouricemia. An increased filtered load of urate cannot explain the high $\mathrm{FE}_{\mathrm{Ur}}$ in our babies with SIADH because the calculated amount of uric acid filtered at the glomerulus during water restriction was inversely related to $\mathrm{FE}_{\mathrm{Ur}}$ (Table 1). Moreover, the clearance of urate was increased in the SIADH infants. This clearly is a secondary consequence of the water-expanded state since serum urate rose and urate clearance returned to normal after restoration of normal serum osmolality by water restriction. The correlation between $\mathrm{FE}_{\mathrm{Ur}}$ and $\mathrm{FE}_{\mathrm{Na}}$ in our subjects (Fig. 4) is consistent with this interpretation and indicates that net urate reabsorption is influenced by the state of hydration of the ECFV.

It is unlikely that a direct action of AVP on renal transport of urate is responsible for the increased clearance of urate in the SIADH patients. AVP, in the absence of volume expansion, has been shown to decrease urate clearance (30). Further, it has been demonstrated that AVP promotes the reabsorption of urate across the toad bladder (31). Thus our results suggest that hypouricemia is common in newborns with SIADH. The hypouricemia in such infants seem to be due to increased urate clearance 
secondary to volume expansion. Although the coexistence of hypouricemia and hyponatremia may provide a helpful clue favoring the diagnosis of SIADH, other possibilities must be considered. The combination may occur, for example, in hereditary renal tubular disorders, such as Wilson disease, Hartnup disease (32), Fanconi syndrome, and severe liver disease $(27,33)$.

Acknowledgments. The authors thank Dr. Dharmapuri Vidyasagar for his support and for the opportunity to perform these studies in the newborn nursery. We thank Mrs. Linda Fornell for her skillful technical assistance and Ms. Gerald Gardner for secretarial help.

\section{REFERENCES}

1. Feldman W, Drummon KN, Klein M 1970 Hyponatremia following asphyxia neonatorum. Actà Pediatr Scand 59:52-57

2. Kaplan SL, Feigim RD 1978 Inappropriate secretion of antidiuretic hormone complicating neonatal hypoxic-ischemic encephalopathy. J Pediatr 92:431433

3. Mor J, Ben Galem E, Abrahamov A 1975 Inappropriate antidiuretic hormone secretion in an infant with severe pneumonia. Am J Dis Child 129:133-135

4. Paxson CL Jr, Stoener JW, Denson SE, Adcock EW, Morriss FH 1977 Syndrome of inappropriate antidiuretic hormone secretion in neonates with pneumothorax or aletactasis. J Pediatr 91:459-463

5. Reynolds DW, Dweck HS, Cassady G 1972 Inappropriate antidiuretic hormone secretion in neonate with meningitis. Am J Dis Child 123:251-253

6. Rees L, Brook CGD, Shaw JCL, Forsling ML 1984 Hyponatremia in the first week of life in preterm infants. Part I. Arginine vasopressin secretion. Arch Dis Child 59:414-422

7. Bartter FC, Schwartz WB 1967 The syndrome of inappropriate secretion of antidiuretic hormone. Am J Med 42:790-806

8. Goldberg M 1963 Hyponatremia and the inappropriate secretion of antidiuretic hormone. Am J Med 35:293-298

9. Berl T, Anderson RJ, McDonald KM, Schrier RW 1976 Clinical disorders of water metabolism. Kidney Int 10:117-132

10. Schedl HP, Bartter FC 1960 An explanation for an experimental correction of the abnormal water diuresis in cirrhosis. J Clin Invest 39:248-261

11. Holmes EW, Kelly WN, Wyngaarden JB 1972 The kidney and the uric acid excretion in man. Kidney Int 2:115-118

12. Steele TH 1969 Evidence for altered renal urate reabsorption during changes in volume of the extra cellular fluid. J Lab Clin Med 74:288-299

13. Weinman EJ, Eknoyan G, Suki WN 1975 The influence of the extra cellular fluid volume on the tubular reabsorption of uric acid. J Clin Invest 55:283291

14. Norman ME, Assadi FK 1979 A prospective study of acute renal failure in the newborn infant. Pediatrics 63:475-479

15. Croxton FE 1959 Elementary Statistics with Applications in Medicine and the Biological Sciences. Dover Publications, New York

16. Robertson GL, Mahr EA, Athar S, Sinha T 1973 Development and clinical application of a new method for the radioimmunoassay of AVP in human plasma. J Clin Invest 52:2340-2352

17. Miller M, Moses AM 1972 Urinary antidiuretic hormone in polyuric disorders and in inappropriate ADH syndrome. Ann Intern Med 77:715-721

18. Gutman AB, Yü TF 1961 A three-component system or regulation of renal excretion of uric acid in man. Trans Assoc Am Phys 74:353-365

19. Diamond HS, Paolino JS 1973 Evidence for a post secretory reabsorption site for uric acid in man. J Clin Invest 52:1491-1499

20. Rieselback RE, Steele TH 1974 Influence of the kidney upon urate homeostasis in health and disease. Am J Med 56:665-675

21. Horster M, Valtin H 1971 Postnatal development of renal function: micropuncture and clearance studies in the dog. J Clin Invest 50:779-795

22. Mees EJD, Van Assendelft BB, Nieuwenhuis MG 1971 Evaluation of uric acid clearance caused by inappropriate antidiuretic hormone secretion. Acta Med Scand 189:69-72

23. Beck LH 1979 Hypouricemia in the syndrome of inappropriate secretion of antidiuretic hormone. N Engl J Med 301:528-530

24. Christiansson G, Josephson B 1960 The uric acid concentration in serum from children newborn infants and mothers after delivery. Acta Pediatr 49:633634

25. Monkus JE, Nyhan WL, Fogel BJ, Yankow S 1970 Concentrations of uric acid in the serum of neonatal infants and their mothers. Am $\mathrm{J}$ Obstet Gynecol 108:91-97

26. Raivio KO 1976 Neonatal hyperuricemia. J Pediatr 88:625-630

27. Ramsdell CM, Kelley WN 1973 The clinical significance of hypouricemia. Ann Intern Med 78:239-242

28. Paswell JH, Modan M, Brish M, and Biochus H 1974 Fractional excretion of uric acid in infancy and childhood: index of tubular maturation. Arch Dis Child 49:878-882

29. Stapleton FB 1983 Renal uric acid clearance in human neonates. J Pediatr 103:290-294

30. Meisel A, Diamond H 1976 Effect of vasopressin on uric acid excretion: evidence for distal nephron reabsorption of urate in man. Clin Sci Mol Med 51:33-40

31. Levine SD, Franki N, Einhorn R, Hays RM 1976 Vasopressin-stimulated movement of drugs and uric acid across the toad urinary bladder. Kidney Int 9:30-35

32. Weitz R, Sperling O 1980 Hereditary renal hypouricemia: isolated tubular defect of urate reabsorption. J Pediatr 96:850-853

33. Dwosh IL, Roncari DAK, Marliss E, Fox IG 1977 Hypouricemia in disease: a study of different mechanisms. J Lab Clin Med 90:153-161 